\title{
Height Cycles in the 18th and 19th Centuries*
}

\author{
Ulrich Woitek ${ }^{\dagger}$ \\ University of Glasgow, Department of Economics
}

May 1998

\begin{abstract}
In this paper, the cyclical structure of 19 th century US and 18th19th century European height data is analyzed. Maximum Entropy spectral analysis of the physical stature of West Point cadets, Citadel students, African Americans, and Austrian soldiers reveals cyclical structure similar to the classical business cycle: a longer cycle with a length of 7-8 years, and a shorter cycle with a length of 3-5 years.

The correlation between height cycles and cycles in economic variables, such as real wages or grain prices, indicates an influence of cycles in economic activity on physical stature. The phase shift between the cycles shows that economic conditions are especially important in infancy. In part this result is due to a cumulative effect: born into a recessionary period, a child is likely to face a second and third cyclical downturn at an age when the body is again sensitive to malnutrition.
\end{abstract}

*I am indebted to Brian A’Hearn, Jörg Baten, Helge Berger, Lee Craig, Michael Haines, Markus Heintel, John Komlos, and the participants of the conference The Biological Standard of Living and Economic Development: Nutrition, Health and Well Being in a Historical Perspective in Munich, Jan. 1997 for helpful comments and suggestions.

${ }^{\dagger}$ University of Glasgow, Department of Economics, Adam Smith Building, Glasgow G12 8RT, email: u.woitek@socsci.gla.ac.uk. 


\section{Introduction}

Changes in physical stature indicate changes in (net) nutritional status. ${ }^{1}$ Quality and quantity of food intake depend on economic conditions, at least in economies in which food expenditure is an important component of total expenditure. In such an economy, heights are an indicator for economic activity, and we shall investigate the extent to which changes in heights reflect not only overall growth of the economy but also short- or mediumterm business fluctuations.

An important result of recent anthropometric research is that time series of US- and European heights in the last two centuries exhibit a typical longterm fluctuation, beginning with a moderate increase in average height at the beginning of the 19th century, followed by a decrease in the middle of the century, while at the end of the century, one observes an increase up to a level higher than in the first half of the century. The purpose of this paper is to present evidence that in addition to this long-term fluctuation in the 18th and 19 th centuries, there are also cyclical, i.e. periodic short- and mediumterm patterns in height series. Moreover, we also analyze the correlation between these height cycles and cyclical patterns in economic fluctuations. ${ }^{2}$

The following issues concerning the nature of height cycles will be examined: (1) Are there regularities in the fluctuations of the height indices

\footnotetext{
${ }^{1}$ Net nutritional status is the quantity and quality of food intake net of minimum necessities, which is reflected in changes in the average height of a sample (see the overview in Steckel (1995)).

${ }^{2}$ It is a a well established fact that business fluctuations exhibit regular patterns in the form of quasi cycles as defined by Frisch (1933). A quasi cycle is not a sine or cosine wave with fixed periodicity, but a time series which exhibit a more or less regular pattern. In the words of Frisch (1933), p. 183: [...] the length of the period and also the amplitude [is] to some extent variable, their variations taking place, however, within such limits that it is reasonable to speak of an average period and an average amplitude. Frisch illustrates this view of a cycle with the example of a dampened pendulum, subject to erratic shocks.
} 
around their time trend? (2) What are the characteristics of the fluctuations of economic activity? (3) Is there a correlation between the height cycles and the economic cycles, and what are the lead-lag relationships between them? The structure of the fluctuations is analyzed using spectral estimation in order to obtain as much information as possible on the existence and length of the height cycles.

\section{Data}

We examine data of West Point cadets, Citadel students, Maryland free blacks, and Austrian soldiers. ${ }^{3}$ As index of economic activity the real wage indices constructed by Goldin and Margo (1992) (observation period: 18251856) and Williamson (1995) (observation period: 1825-1900) were chosen. These are reasonable choices, since changes in real wages reflect changes in the budget constraint, and hence, changes in the quality and quantity of food purchased by the households. The index of Williamson (1995) is a national average; while the indices of Goldin and Margo (1992) are regional. Since the West Point cadets were mainly from the Northeast and Midwest (see Komlos (1987), Table 1, p. 900), only the wages for these regions are examined (artisans, laborers, and clerks). For the Austrian heights, the fluctuations of annual grain prices from Vienna are used as economic indicator (Pribram, ed (1938), p. 371-373).

\footnotetext{
${ }^{3}$ I am grateful to John Komlos for providing me with the data sets. West Point cadets: Komlos (1987), observation period: 1825-1876 (birthyear); the sample is restricted to 1621 year old cadets; Citadel students: Coclanis and Komlos (1995); observation period: 1825-1876 (birthyear); the sample is restricted to 16-21 year old students; Maryland free blacks: Komlos (1992); observation period: 1790-1840 (birthyear); the sample is restricted to the age group 16-40 years; Austrian soldiers: Komlos (1989); the sample is restricted to the observation period 1746-1800 (birthyear) and to the age group 16-40 years.
} 
In the next step, we construct annual time series from these data sets; ${ }^{4}$ the number of annual observations ranges between about 30 (Citadel students) to 1000-2000 (Austrian soldiers). Annual series based on these small samples will show variations which are not interpretable, i.e. which must be looked upon as noise. The next problem we face is that the heights are from individuals in different age groups. Following the method in the literature, we correct for age differences by dividing the heights by the mean of the respective age group in the observation period. ${ }^{5}$

For the Maryland free blacks, we analyze two series, disaggregated into male and female heights. The average annual sample size for the Austrian soldiers is large enough to allow the construction of height series for several age groups. This enables us to look at business cycle influences on the heights along the growth curve: it is likely that the heights of younger ages (16-18 years) are more volatile and more subjected to business conditions in infancy than adult heights ( $>21$ years), because catch-up growth might lead to smoother fluctuations around the overall trend. ${ }^{6}$

\section{Method}

It has been shown that estimates of cyclical structure are sensitive to detrending methods: if the long-run component of a series is of the randomwalk type, a long 'classical' business cycle (7-9 years) can be generated by an

\footnotetext{
${ }^{4}$ All series are available on request

${ }^{5}$ For the Citadel students, the West Point cadets, and the Maryland Free blacks the age groups are 16-18 years, 19-21 years, and $>21$ years.

${ }^{6}$ In addition to the overall index of the West Point cadets, a breakdown into 6 series was analyzed, dependent on the occupation of the father (no profession, farmer, blue collar, merchant, professional, and government (see Komlos (1987), p. 902)), in order to qualify the influence of the business cycle on different classes of society. Since it was not possible to find a clear-cut pattern due to the small-sample problem, the results are not reported here.
} 
incorrect data transformation, e.g. a linear time trend. On the other hand, using a difference filter on a series which is not of the random-walk type will exaggerate the relative importance of short cycles. ${ }^{7}$

Before we can analyze the cyclical structure of the series, we need stationary series, i.e. series for which the mean and the variance are timeindependent. This is certainly not the case for the series analyzed here, since all of them exhibit the long-run pattern mentioned in the introduction. One could try to decide whether a series is integrated (contains at least one unit root) or whether it is trend stationary, applying the tests designed by Dickey (1976) and Fuller (1976). But these tests are known to be biased in favour of the unit root hypothesis. Given their limited reliability, it is preferable to test for robustness under different assumptions on the type of non-stationarity: Both the Hodrick-Prescott (HP-) filter (Hodrick and Prescott (1980)) $)^{8}$ and the difference filter are used. If the results for both detrending methods are similar, we can be sure that the cyclical structure is not artificial.

Once we have a stationary series, we can start to examine the cyclical structure in the frequency domain, which is the best choice if we want to look for quasi cycles. Transforming a series from time to frequency domain means representing it as a superimposition of cycles with frequencies in the interval $[0,0.5] .{ }^{9}$ In order to judge the relative importance of each cyclical component for the overall variance of the series, we compute the spectrum,

\footnotetext{
${ }^{7}$ Following the influential papers of Chan et al. (1977) and Nelson and Plosser (1982), there is a body of literature analyzing the distorting effects of a wrongly chosen detrending procedure. A recent example is King and Rebelo (1993), who explicitly examine the effects of the filters used in this paper.

${ }^{8}$ In the following, a HP-filter with smoothing weight $\mu=100$ (annual data) is used.

${ }^{9}$ The respective period can be obtained from the reciprocal value of the frequency. The maximum frequency of 0.5 corresponds to a minimum identifiable cycle length of 2 time units, in our case two years.
} 
which is the analogue of the autocovariance function in frequency domain: ${ }^{10}$ The contribution of each component is plotted against the corresponding frequency in the interval $[0,0.5]$; a peak in the spectrum indicates a large contribution and therefore a relative important cyclical component.

The classical spectral estimate, the periodogram, is not suited for economic time series because these are notoriously very short. A method which is preferable with respect to the length of the observation period is the Maximum Entropy (ME) approach of Burg (1975). In addition, an ME-spectrum can be easily computed. First, an AR-model is fit to the data. ${ }^{11}$ To obtain the ME-spectrum, the estimated models are transformed from time to frequency domain. ${ }^{12}$ From these spectra, measures for the cyclical structure are derived; the interpretation of these measures is presented in the Appendix.

\section{Results}

The means and standard deviations of the difference filtered height series ${ }^{13}$ show that on the one hand, the average year-to-year percentage change is not dramatic and takes values near 0 , which is reasonable. On the other hand, the standard deviations and therefore the volatility of the series are high; on average, we have a standard deviation of about 1 per cent (Table 1), a result which can be attributed to the small annual samples.

Among the Austrian soldiers, the volatility is higher the younger are

\footnotetext{
${ }^{10}$ See e.g. the introduction in Harvey (1993).

${ }^{11}$ The model can be univariate or multivariate, dependent on whether one is interested in the cyclical structure of a single series or in the lead-lag relationship between cycles in different series (the order of the AR-models is determined using standard procedures from the literature (AIC)). Burg (1975) has shown that the spectrum of an AR model is formally identical to the spectral estimate derived applying the ME-principle.

${ }^{12}$ For an application to the analysis of historical time series and a detailed explanation see Bauernfeind and Woitek (1996).

${ }^{13}$ In the following, all data are in logs.
} 
the recruits. An obvious interpretation is that the first age group was still strongly influenced by the business conditions in the birth year, catch-up growth eventually lead to a smoothing of this influence in the later age groups, leading to a smaller standard deviation of the year-to-year changes.

Table 1: Height Series, Descriptive Statistics (Annual Growth Rates)

\begin{tabular}{llrr}
\hline \hline & & Mean $^{1}$ & Standard Deviation $^{1}$ \\
\hline West Point Cadets & & -0.01 & 1.01 \\
$(1825-1876)$ & & \\
Citadel Students & & 0.06 & 1.29 \\
$(1865-1900)$ & & -0.00 & 0.76 \\
Maryland Free Blacks & Male & -0.05 & 0.92 \\
$(1790-1840)$ & Female & -0.04 & 0.94 \\
Austrian Soldiers & 16-18 years & -0.03 & 0.62 \\
$(1746-1800)$ & 19-21 years & -0.06 & 0.23 \\
& $>21$ years & &
\end{tabular}

${ }^{1}$ In per cent

A first look at the signal-to-noise ratio $(\mathrm{SNR})^{14}$ shows that it is in general less than 1 for both filtering methods and all data sets (Tables 2 and 3). Obviously, the fluctuations around the trend are dominated by noise. This is a reasonable outcome: given that the annual sample size of the height series is very small, one would expect 'spurious' year-to-year variations. Since the 'regular' part of the fluctuations is small compared to the noise, we can be confident that it is not caused by the aggregation method. Nevertheless, there is structure in the series: the order of the AR-models is, with only a few exceptions, higher than 0 .

\footnotetext{
${ }^{14}$ See the Appendix for a definition of the spectral measures used in this section.
} 
Table 2: HP-filtered Heights, Univariate Spectra

\begin{tabular}{lrrrrrr}
\hline \hline & Period & $p p$ & Moduli & $b w$ & SNR & Order \\
\hline West Point Cadets & 7.05 & 0.21 & 0.82 & 3.36 & 0.33 & 4 \\
$(1825-1876)$ & 2.93 & 0.10 & 0.65 & - & & \\
Citadel Students & - & - & - & - & - & 0 \\
$(1865-1900)$ & & & & & & \\
Maryland Free Blacks (M) & 5.27 & 0.13 & 0.67 & 4.47 & 0.12 & 3 \\
(1790-1840) & & & & & & \\
Maryland Free Blacks (F) & 3.46 & 0.22 & 0.56 & 2.79 & 0.14 & 2 \\
(1790-1940) & & & & & & \\
Austrian Soldiers(1746-1800) & & & & & & \\
$16-18$ years & 5.20 & 0.19 & 0.66 & 5.07 & 0.35 & 2 \\
19-21 years & 6.66 & 0.15 & 0.64 & 26.50 & 0.56 & 2 \\
$>21$ years & 5.37 & 0.24 & 0.82 & 2.25 & 0.47 & 4 \\
\hline
\end{tabular}

pp: peak power; bw: bandwidth; SNR: signal-to-noise ratio

(See the Appendix for an explanation of the measures.)

Table 3: Difference-filtered Heights, Univariate Spectra

\begin{tabular}{llrrrrr}
\hline \hline & Period & $p p$ & Moduli & $b w$ & SNR & Order \\
\hline West Point Cadets & 7.06 & 0.13 & 0.87 & 2.39 & 0.37 & 6 \\
$(1825-1876)$ & 3.62 & 0.17 & 0.76 & - & & \\
& 2.47 & 0.21 & 0.76 & - & & \\
& 2.60 & 0.29 & 0.47 & - & 0.32 & 2 \\
Citadel Students & & & & & & \\
(1865-1900) & 3.95 & 0.12 & 0.65 & - & 0.55 & 3 \\
Maryland Free Blacks (M) & & & & & & \\
(1790-1840) & 3.01 & 0.39 & 0.72 & 1.00 & 0.72 & 2 \\
Maryland Free Blacks (F) & & & & & & \\
(1790-1840) & & & & & & \\
Austrian Soldiers (1746-1800) & & & & & \\
16-18 years & 4.99 & 0.40 & 0.90 & 0.88 & 0.85 & 4 \\
19-21 years & 5.76 & 0.24 & 0.84 & 1.98 & 0.42 & 4 \\
& 2.87 & 0.18 & 0.72 & - & & \\
$>21$ years & 5.02 & 0.28 & 0.85 & 1.37 & 0.60 & 3 \\
\hline
\end{tabular}

$p p$ : peak power; bw: bandwidth; SNR: signal-to-noise ratio

(See the Appendix for an explanation of the measures) 


\section{Figure 1: Height Cycles}

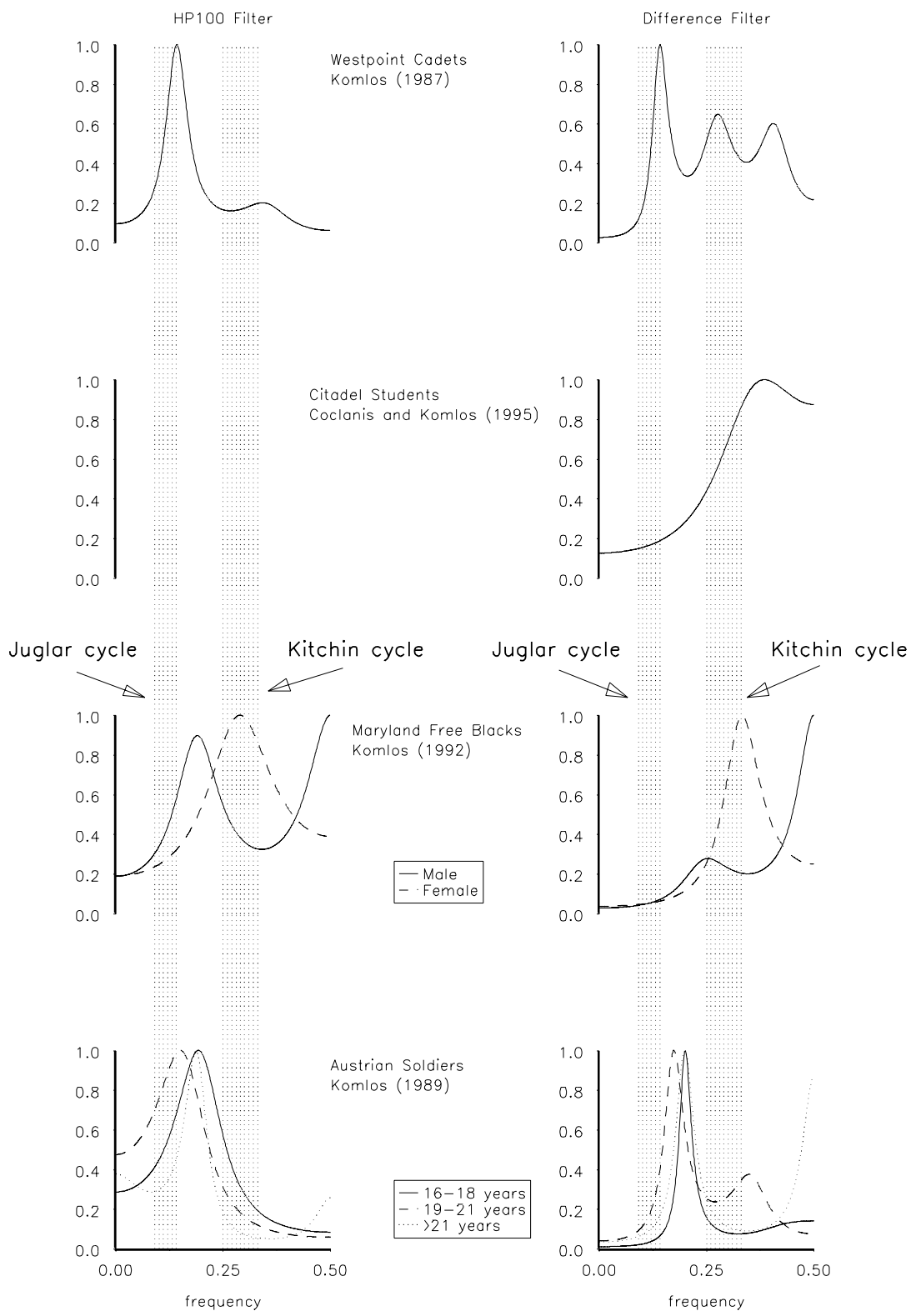

Note:

The spectra are normalized (divided by their maximum value) in order to make a comparison of the spectral shapes possible. The shaded area indicates the frequency bands for the 'classical' business cycle (Juglar cycle: $7-9$ years; Kitchin cycle: $3-5$ years). A missing spectrum indicates order 0 . 
For the West Point cadets, univariate analysis indicates cycles with a length of 7 and 3 years for both filtering methods (Tables 2-3 and Figure 1). The different shapes of the two spectra are as expected: for the difference filter, most of the mass is in the high frequency range; for the HP-filter, it is reversed. This difference influences only the relative importance of the cycles. Since the cycle lengths are the same in both cases, we can infer that the cyclical structure is not artificial.

In the case of the HP filtered Citadel index, one does not find any cyclical structure at all, while after differencing, the short cycle can be seen in the spectrum (Table 2 and 3, Figure 1). This means that the cyclical structure is certainly not robust, and we have to be careful when interpreting the multivariate results.

The cycle in the spectra of the free blacks lies in between the frequency bands of the classical business cycle. But at least we can be sure that the cycles are not spurious, insofar as the results for the difference filtered series are similar to those of the HP filtered series. We see that the cyclical structure is more important in the spectrum of the women than in that of the men.

A possible explanation might be that the higher market value of the male slaves lead to a higher nutritional status of males, ${ }^{15}$ reflected in physical stature which is less subjected to cyclical fluctuations. But even if we assume that intra-household allocation of nutrients was not entirely decided by the slaveowner, one can infer that females suffered more in crisis years, i.e. were more subjected to the business cycle, because males had a higher 'expected income'. Therefore it was preferable to provide them with a higher quantity

\footnotetext{
${ }^{15}$ Komlos (1992), p. 303, Table 10.1 reports that 70 per cent of the sample consists of African Americans who were born as slaves. Therefore the decision of the slaveholder about food allocation has to be taken into account when thinking about explanations of height cycles in this sample.
} 
and quality of food, independently of price fluctuations.

Taken together, the height series under analysis clearly exhibit a cyclical pattern. The result is important because the cycles correspond to types of fluctuations well known in empirical business cycle research, namely the Juglar-cycle (7-9 years) and the short Kitchin-cycle (3-5 years).

We next explore the cyclical structure of the economic indicators. All three Vienna grain price series exhibit cyclical structure with similar characteristics as the 'classical' business cycle stylized facts mentioned in the introduction. The only exception is wheat, for which the difference filtered series does not exhibit structure at all.

Table 4: Vienna Grain Prices, Univariate Spectra HP Filter

\begin{tabular}{|c|c|c|c|c|c|c|}
\hline & Period & $p p$ & Moduli & $b w$ & $\overline{\mathrm{SNR}}$ & Order \\
\hline Wheat & 7.63 & 0.12 & 0.57 & $\begin{array}{lll}- & \\
\end{array}$ & 0.50 & 2 \\
\hline Rye & 6.92 & 0.15 & 0.63 & - & 0.59 & 2 \\
\hline Barley & 6.33 & 0.13 & 0.58 & - & 0.35 & 2 \\
\hline \multicolumn{7}{|c|}{ Difference Filter } \\
\hline & Period & $\overline{p p}$ & Moduli & $b w$ & $\overline{\mathrm{SNR}}$ & Order \\
\hline Wheat & - & - & - & - & - & 0 \\
\hline Rye & 4.25 & 0.20 & 0.60 & 3.81 & 0.16 & 2 \\
\hline \multirow[t]{2}{*}{ Barley } & 7.48 & 0.09 & 0.85 & - & 0.45 & 6 \\
\hline & 4.12 & 0.26 & 0.84 & 1.06 & & \\
\hline
\end{tabular}

$p p$ : peak power; $b w$ : bandwidth; SNR: signal-to-noise ratio (See the Appendix for an explanation of the measures.) 


\section{Figure 2: Cycles in Real Wages}

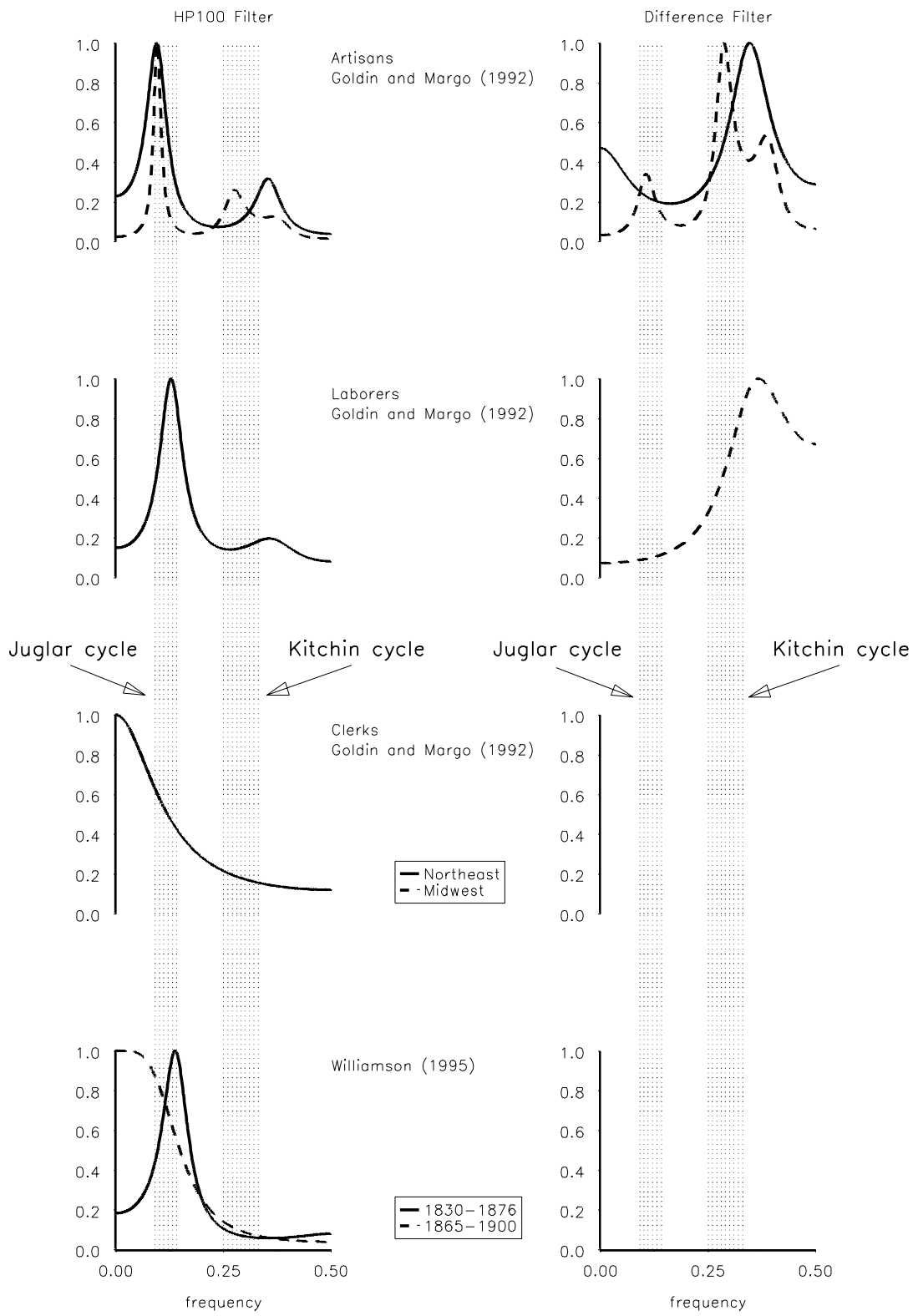

Note:

The spectra are normalized (divided by their maximum value) in order to make a comparison of the spectral shapes possible. The shaded area indicates the frequency bands for the 'classical' business cycle (Juglar cycle: $7-9$ years; Kitchin cycle: $3-5$ years). A missing spectrum indicates order 0 . 
The univariate spectra of wages of artisans, laborers and clerks from Northeast and Midwest (Goldin and Margo (1992)) show no clear-cut pattern (Figure 2). Robust structure can only be found in the results for the artisan wages, while the cycles in the laborer wages clearly depend on the filter method. There is no cyclical structure to be seen in the spectrum of the real wages for clerks. Apparently, the wages for clerks depend less on the cyclical fluctuations of business conditions than the wages for unskilled or less skilled occupations. The spectra for the two subsamples of the Williamson (1995) index also show no robust cyclical structure. ${ }^{16}$

The univariate outcome encourages the extension to the multivariate analysis of the cyclical structure to the Austrian soldiers and to the West Point cadets: ${ }^{17}$ how strong is the relationship between the height cycles and corresponding cycles in economic variables (grain prices and artisan real wages), and what was the lead-lag structure ${ }^{18}$

An obvious finding for the Austrian soldiers (Tables 5 and 6 ) is that the squared coherency is highest for cycles between 5 and 6 years. As it was expected, the peak of the coherency can be found in the frequency band corresponding to the peaks in the univariate height spectra. Comparing the coherencies for the three grain prices and the three age groups, we see that an overall maximum is reached for the adults ( $>21$ years) and the wheat price cycle. This result contradicts the interpretation of the univariate results, but

\footnotetext{
${ }^{16}$ There is no clear evidence on whether real wage cycles are pro- or countercyclical with respect to the business cycle (see the overview in Abraham and Haltiwanger (1995)). For the series under analysis, the result in Figure 2 suggests that, with the exception of artisan wages, it might be not justified to talk about a business cycle in real wages at all.

${ }^{17}$ Unfortunately, we cannot perform a multivariate analysis of the correlation between the cycles in the Maryland data set and economic cycles, because suitable time series on economic activity are not available for this period. For the Citadel students, we would need the real wage series from Williamson (1995). But this series does not exhibit robust cyclical structure, therefore we are forced to stop the analysis here.

${ }^{18}$ See the Appendix for a definition of the measures.
} 
it can be explained as follows: since the two youngest age groups were still growing, the different speeds of catch-up growth might produce a somewhat weaker influence of birthyear economic conditions due to the aggregation process. The gain is especially high for the third age group (> 21 years), which means that inspite of the fact that the coherency is highest, the relative size of the business cycle amplitude is lowest.

Table 5: Grain Prices and Heights (Austrian Soldiers), 1746-1800, Multivariate Spectra, HP Filter

\begin{tabular}{llrrrrr}
\hline \hline & Age Group & Period & $s c$ & Phase & Gain & Order \\
\hline Wheat & $16-18$ & 5.56 & 0.25 & 1.74 & 10.33 & 3 \\
& $19-21$ & 5.75 & 0.43 & -2.14 & 22.49 & 3 \\
& & 2.56 & 0.13 & 0.65 & 13.99 & \\
& $>21$ & 5.49 & 0.46 & $1.53^{\star}$ & 66.74 & 3 \\
Rye & & 2.35 & 0.12 & -0.77 & 29.30 & \\
& $16-18$ & 5.56 & 0.05 & 1.63 & 6.53 & 3 \\
& $19-21$ & 10.31 & 0.38 & $2.62^{\star}$ & 28.44 & 3 \\
& & 6.10 & 0.33 & -2.80 & 25.98 & \\
& & 2.74 & 0.18 & $0.74^{\star}$ & 17.13 & \\
& & 10.99 & 0.40 & -4.33 & 95.27 & 3 \\
\multirow{6}{*}{ Barley } & 5.29 & 0.46 & $1.29^{\star}$ & 90.06 & \\
& $16-18$ & 2.39 & 0.07 & -0.81 & 22.36 & \\
& $19-21$ & 7.35 & 0.14 & 0.81 & 10.70 & 2 \\
& & 6.17 & 0.36 & -2.84 & 20.26 & 3 \\
& & 2.81 & 0.23 & $0.75^{\star}$ & 18.71 & \\
& & 10.75 & 0.27 & -3.59 & 56.20 & 3 \\
& & 5.10 & 0.40 & $1.23^{\star}$ & 72.46 & \\
\hline
\end{tabular}

sc: squared coherency

Phase: phase lead of price cycle over height cycle

${ }^{\star}{ }^{\star}$ : significant on the 10 per cent level)

Gain: relative size of price cycle amplitude to height cycle amplitude

First line: long cycle; second line: short cycle

(See the Appendix for an explanation of the measures) 
Table 6: Grain Prices and Heights (Austrian Soldiers), 1746-1800, Multivariate Spectra, Difference Filter

\begin{tabular}{llrrrrr}
\hline \hline & Age Group & Period & $s c$ & Phase & Gain & Order \\
\hline Wheat & $16-18$ & 5.81 & 0.31 & $1.54^{\star}$ & 14.47 & 3 \\
& $19-21$ & 5.43 & 0.38 & -2.33 & 21.34 & 3 \\
& & 2.77 & 0.20 & 0.42 & 15.29 & \\
& & 5.15 & 0.40 & $1.61^{\star}$ & 53.61 & 3 \\
Rye & \multirow{2}{*}{$16-18$} & 2.27 & 0.17 & -0.65 & 32.74 & \\
& & 7.04 & 0.33 & $1.22^{\star}$ & 23.26 & 3 \\
& \multirow{2}{*}{$19-21$} & 4.48 & 0.11 & -1.56 & 7.59 & \\
& & 5.35 & 0.29 & -2.43 & 24.40 & 3 \\
& & 2.72 & 0.27 & $0.63^{\star}$ & 20.27 & \\
& & 9.09 & 0.09 & -3.86 & 38.73 & 3 \\
Barley & & 4.83 & 0.43 & $1.27^{\star}$ & 81.94 & \\
& \multirow{2}{*}{$16-18$} & 2.30 & 0.14 & -0.67 & 29.77 & \\
& & 6.41 & 0.35 & $1.41^{\star}$ & 15.71 & 3 \\
& \multirow{4}{*}{$19-21$} & 4.33 & 0.16 & -1.34 & 8.89 & \\
& & 2.44 & 0.36 & $0.63^{\star}$ & 13.27 & \\
& & 5.26 & 0.32 & -2.31 & 19.15 & 3 \\
& & 2.82 & 0.32 & $0.65^{\star}$ & 22.27 & \\
& & 10.20 & 0.03 & -3.43 & 16.19 & 3 \\
\hline
\end{tabular}

sc: squared coherency

Phase: phase lead of price cycle over height cycle

( ${ }^{\star}$ : significant on the 10 per cent level)

Gain: relative size of price cycle amplitude to height cycle amplitude

First line: long cycle; second line: short cycle

(See the Appendix for an explanation of the measures) 
When interpreting the phase shift, we have to bear the following problem in mind: assume two series $X$ and $Y$ with a cycle of 8 years, and for $Y$ a phase lag of 2 years. Adding a full cycle length to the phase we obtain a phase lead of 6 years. The resulting phase shift depends therefore on the choice of the observation period, i.e. the starting values for the cycles. In order to overcome this problem, we construct confidence intervals for the phase shift using Runkle's bootstrap method (Runkle (1987)). ${ }^{19}$ This resampling procedure changes the starting values for the replications, and thus makes it possible to identify significant phase leads/lags.

The results for the phase shift show a very clear pattern: at the peak frequencies of the coherence spectrum (which correspond approximately to the peak frequencies from the univariate spectra), the grain price cycle significantly leads the height cycle with a shift of 1-2 years, especially for the third age group. For the other age groups the result is not so strong, but we see that whenever the phase shift is significant, it indicates a lead of the price cycle over the height cycle.

To interprete this outcome, it is helpful to look at Figure 3. Let us assume a cycle of $\frac{1}{\lambda}=6$ years length, and compare two upper turning points. A phase shift $\phi$ of 1 year means that the price cycle reaches the upper turning point A 1 year earlier than the height cycle. ${ }^{20}$ The next trough of the price cycle (C) is reached $\frac{0.5}{\lambda}-\phi=2$ years after the birthyear $B$. In other words, due to the decrease in prices in the interval between situation $\mathbf{A}$ and $\mathbf{C}$, the children born in birthyear $\mathbf{B}$ face an improvement of the nutritional status over the first two years of their live, which results in a positive deviation of the height index from its trend in birthyear $\mathbf{B}$.

\footnotetext{
191000 replications.

${ }^{20}$ In the example, we assume a stable demand for grain, and that price fluctuations are due to changes in supply.
} 
Starting with a lower turning point of the height cycle in the birthyear leads to a similar explanation: here, nutritional status deteriorates during the first years of life, which is reflected in a negative deviation of the height index from its trend in the birthyear. Insofar as during the first three years of life, a child is especially at risk of malnutrition (Tanner (1990), p. 131), this pattern is in line with what one would expect the lead-lag relationship to be.

We can conclude from these results that the influence of business conditions on physical stature is especially strong in the first years of the growth phase. Moreover, given the length of the business cycle, we are measuring a cumulative effect: someone who is born in a recession will experience recession again at age 8 and age 16 . Hence, the initial impact will be reinforced at the adolescent growth spurt when the body is again sensitive to nutritional intake. 
Figure 3: The Phase Shift between Price and Height Cycles

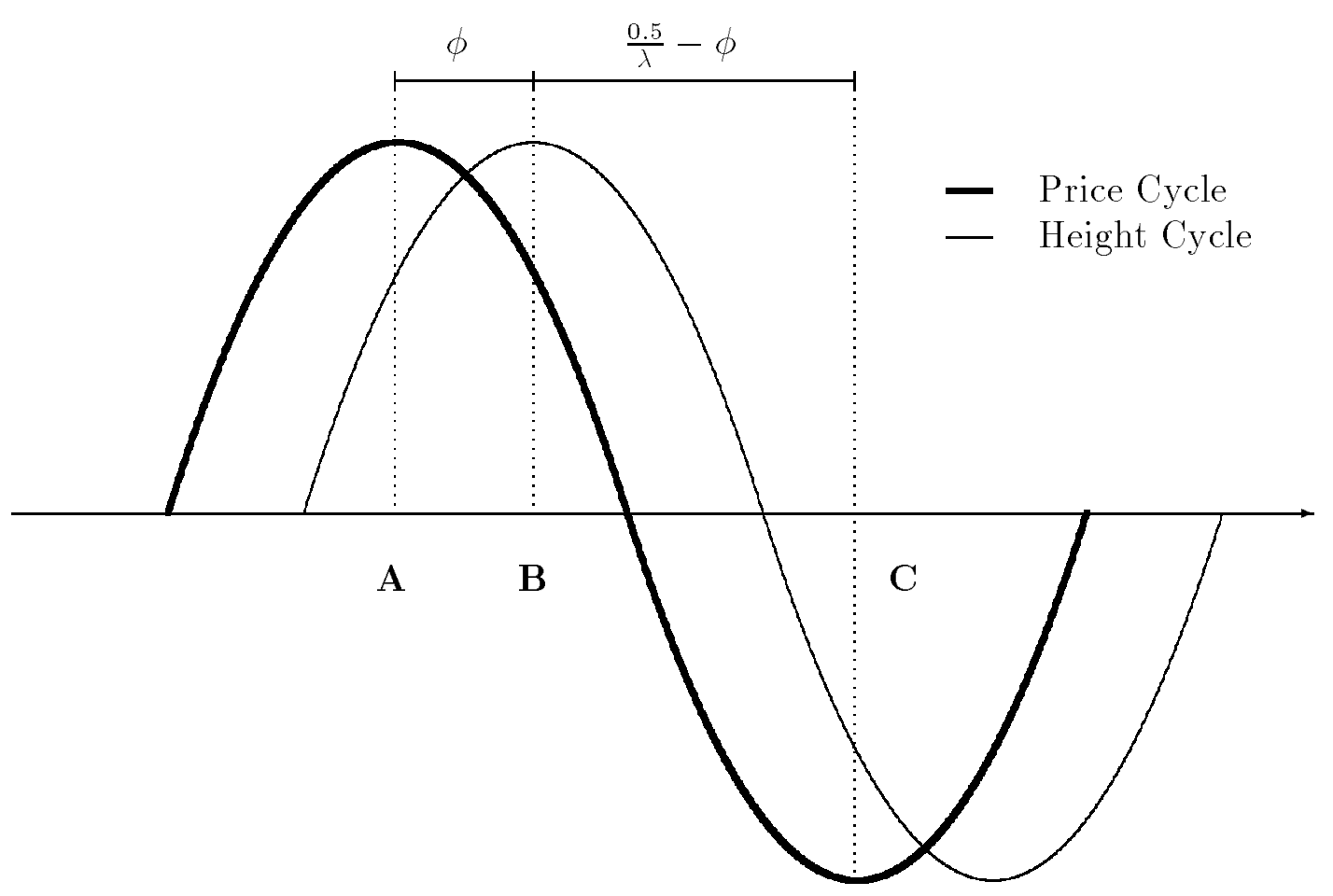

$\phi:$ phase lead

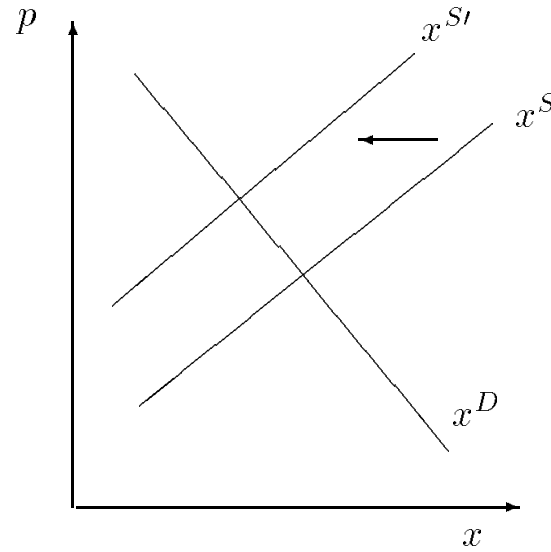

A

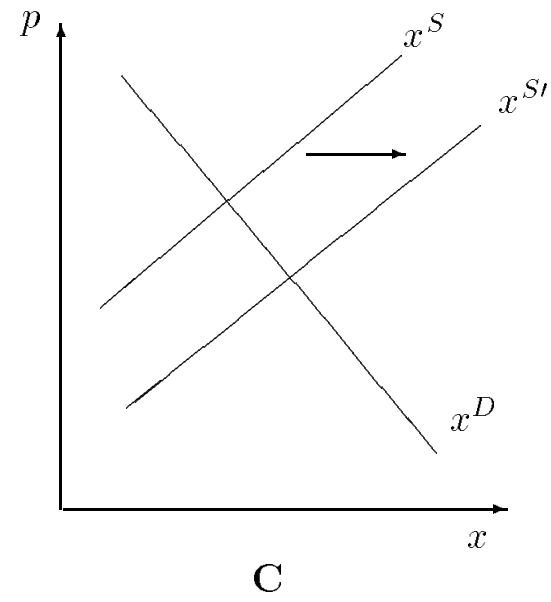

$\lambda:$ frequency

B: birthyear 
Table 7: Real Wages (Goldin and Margo 1992) and Heights (West Point Cadets), 1830-1865, Multivariate Spectra

HP Filter

\begin{tabular}{rrrrrr}
\hline \hline & Period & $s c$ & Phase & Gain & Order \\
\hline Northeast & 6.25 & 0.54 & -2.90 & 6.63 & 3 \\
& 2.63 & 0.75 & $-0.28^{\star}$ & 9.92 & \\
Midwest & 5.71 & 0.26 & 1.75 & 8.66 & 3 \\
& 2.78 & 0.60 & $-0.71^{\star}$ & 16.65 & \\
& Difference Filter & & \\
\hline \hline Northeast & Period & sc & Phase & Gain & Order \\
\hline \multirow{4}{*}{ Midwest } & 5.41 & 0.48 & -2.39 & 5.37 & 3 \\
& 2.67 & 0.85 & -0.22 & 10.75 & \\
& 5.71 & 0.16 & 1.45 & 7.87 & 2 \\
\hline
\end{tabular}

sc: squared coherency

Phase: phase lead of real wage cycle over height cycle

( ${ }^{\star}$ : significant on the 10 per cent level)

Gain: relative size of real wage cycle amplitude

to height cycle amplitude

First line: long cycle; second line: short cycle.

(See the Appendix for an explanation of the measures)

As stated above, robust cyclical structure of wage fluctuations could only be found for the artisan real wages. Therefore, we can only look for the correlation with the cycle in the West Point height series. The squared coherency is higher than for the Austrian Soldiers. Again, the results for the gain show that the height cycles are clearly smaller than the corresponding economic cycles: we have to multiply the amplitude of the heights cycle by 5-20 to get the respective amplitude of the real wage cycle. This is a plausible outcome which demonstrates that the influence of the business cycle, although significant, is only small. For example, Komlos (1987) reports an average decline of $1.4 \mathrm{~cm}$ for the West Point Cadets between 1820 and 1860; given that order 
of magnitude for a change in height over 40 years, the change in the short run due to the business cycle must have been smaller.

There are two important results: the phase shift between the long cycle in heights and real wages is not significantly different from zero, in other words, economic conditions in the birth year are reflected in the long height cycle. For the short cycle the phase shift is significant: the height cycle leads the respective real wage cycle, but the phase shift is less than one year. Since we are looking at annual data, the result cannot be distinguished from a phase shift of zero. Hence, the outcome indicates that economic conditions in the birthyear have an impact on heights. This initial impact has a cumulative effect on heights: a birth cohort in a recession/boom year will face the same economic conditions again at important points during the growth process.

\section{Conclusion}

There are obvious cyclical structures in time series on heights (West Point cadets, Citadel students, Maryland Free Blacks, Austrian soldiers) with characteristics similar to business cycles. We find a correlation between height cycles and cycles in economic activity (real wages, grain prices), a result which suggests that there is a dependence of the physical growth process and economic cycles. ${ }^{21}$

The phase shift between the real wage and height cycles shows that the height cycle leads the economic cycle, whenever it is significantly different

\footnotetext{
${ }^{21}$ An intersting implication of finding a relationship between height cycles and economic cycles is the following: the human growth process is influenced also by exposure to deseases, which lay claim to the nutrients digested. Hence, the amount of nutrient absorbed by the biological system is also a function of the epidemiological environment. The result of a business cycle in heights shows that variations in the desease environment do not suffice to explain variations in heights observed in the 18th and 19th centuries (Komlos and Coclanis (1997), A’Hearn (1998), Komlos (1998)).
} 
from zero. For the grain prices, we find a significant phase lead of the price cycle over the height cycle. One can conclude from these results that the influence of business conditions on physical stature is especially strong in the first years of the growth phase. Moreover, given the length of the business cycle, we are measuring a cumulative effect: someone who is born in a recession will experience recession again at age 8 and age 16 . Hence, the initial impact will be reinforced at the adolescent growth spurt when the body is again sensitive to nutritional intake. Since the sample is heterogeneous, these results are promising, and motivate an extension of the analysis to other data sets of heights and of economic variables. 


\section{Appendix}

\section{Univariate Measures $^{22}$}

\section{- Period}

The period (in years) denotes the cycle length at the peaks of the spectra.

- Peak Power $(p p)$

Peaks in the spectrum indicate components with a large contribution to the overall variance, relative to other components. The Peak Power can be looked upon in the same way as $R^{2}$ in a linear regression model: it measures the 'importance' of cycles with frequencies in an interval \pm 10 per cent around a peak frequency.

- Modulus

The Modulus is the absolute value of the roots in the characteristic polynomial of the AR-model. Each pair of conjugate complex roots corresponds to a peak in the spectrum. The modulus measures the extend to which the respective cycle is damped; a high modulus means a sharp peak in the spectrum, a low modulus means a relative wide peak.

- Bandwidth $(b w)$

The bandwidth is the range over which a peak in the spectrum is reduced by one half (in years): the smaller the bandwidth, the sharper the peak. For peaks which are to close to one another or to close to the border of the frequency interval $[0,0.5]$, the bandwidth cannot be

\footnotetext{
${ }^{22} \mathrm{~A}$ more detailed explanation of the measures can be found in Bauernfeind and Woitek (1996).
} 
computed. It contains essentially the same information as the modulus, but it provides additional insight on the shape of the spectrum.

- Signal-to-Noise Ratio (SNR)

SNR can be interpreted as a goodness-of-fit measure. It is the ratio of the variance of the signal (variance of the estimated model - variance of the estimated noise) to the variance of the estimated noise. The higher SNR, the more 'regular' the structure of the detrended data.

\section{Multivariate Measures}

To measure the lead-lag relationship between the height series and the real wage indices, we estimate a multivariate AR-model and compute the spectral density matrix. From this matrix we derive the following measures: ${ }^{23}$

- Squared Coherency $(s c)$

Suppose the spectra of two series $X$ and $Y$ exhibit peaks at the same frequency $\lambda^{\star}$. sc measures the extent of the linear relationship between the cycles in the two series. It can be interpreted in the same way as the correlation coefficient in a linear regression model.

- Phase Shift

The phase shift measures the lead-lag relationship between two cycles of the same frequency in the series $X$ and $Y$, i.e. the distance between the turning points of cycles with the same frequency.

- Gain

The Gain measures the multiplicative change of the amplitude of a cycle with a certain frequency in series $X$ if transformed to the cycle

\footnotetext{
${ }^{23}$ These measures are computed at the frequencies where the correlation between the cycles in the two series are strongest.
} 
with the same frequency in series $Y$; in other words, with the gain it is possible to judge the relative size of the amplitudes of cycles with the same frequencies in the two series. 


\section{References}

Abraham, K. G. and J. C. Haltiwanger, "Real Wages and the Business Cycle," Journal of Economic Literature, 1995, XXXIII, 1215-1264.

A'Hearn, B., "The Antebellum Puzzle Revisited: A New Look at the Stature of Union Army Recruits during the Civil War," in J. Komlos and J. Baten, eds., The Biological Standard of Living in Comparative Perspective, Stuttgart: Franz Steiner, 1998.

Bauernfeind, W. and U. Woitek, "Agrarian Cycles in Germany 13391670: A Spectral Analysis of Grain Prices and Output in Nuremberg," Explorations in Economic History, 1996, 33, 459-478.

Burg, J. P., "Maximum Entropy Spectral Analysis." PhD dissertation, Stanford University 1975.

Chan, K. H., J. C. Hayya, and J. K. Ord, "A Note on Trend Removal Methods: The Case of Polynomial Regression Versus Variate Differencing," Econometrica, 1977, 45, 737-744.

Coclanis, P. A. and J. Komlos, "Nutrition and Economic Development in Post-Reconstruction South Carolina," Social Science History, 1995, 19, $91-115$.

Dickey, D. A., "Estimation and Hypothesis Testing in Nonstationary Time Series." PhD dissertation, Iowa State University 1976.

Frisch, R., "Propagation Problems and Impulse Problems in Dynamic Economics," in "Economic Essays in Honor of Gustav Cassel," London: George Allen \& Unwin, 1933. Reprinted in Gordon and Klein (1965). 
Fuller, W. A., Introduction to Statistical Time Series, New York, Chichester, Brisbane, Toronto, Singapore: John Wiley \& Sons, 1976.

Goldin, C. and R. A. Margo, "Wages, Prices and Labor Markets before the Civil War," in C. Goldin and H. Rockoff, eds., Strategic Factors in Nineteenth Century American Economic History, Chicago, London: University of Chicago Press, 1992, chapter 2, pp. 67-104.

Gordon, R. A. and L. R. Klein, Readings in Business Cycles, Homewood, Ill.: Richard D. Irwin, 1965.

Harvey, A. C., Time Series Models, 2nd ed., New York, London, Toronto, Sydney, Tokio, Singapore: Harvester Wheatsheaf, 1993.

Hodrick, R. and E. Prescott, "Postwar U.S. Business Cycles: An Empirical Investigation," 1980. Discussion Paper No. 451, Carnegie-Mellon University.

King, R. G. and S. T. Rebelo, "Low Frequency Filtering and Real Business Cycles," Journal of Economic Dynamics and Control, 1993, 1\%, 207231.

Komlos, J., "The Height and Weight of West Point Cadets: Dietary Change in Antebellum America," Journal of Economic History, 1987, 47, 897-927.

_, Nutrition and Economic Development in the Eighteenth-Century Habsburg Monarchy, Princeton, New Jersey: Princeton University Press, 1989.

_, "Toward an Anthropometric History of African-Americans. The Case of Free Blacks in Antebellum Maryland," in C. Goldin and H. Rockoff, eds., Strategic Factors in Nineteenth Century American Economic History, 
Chicago, London: University of Chicago Press, 1992, chapter 10, pp. 297329.

_, "Shrinking in a Growing Economy? The Mystery of Physical Stature during the Industrial Revolution," Journal of Economic History, 1998. forthcoming.

_ and P. Coclanis, "On the Puzzling Cycle in the Biological Standard of Living: The Case of the Antibellum Georgia," Explorations in Economic History, 1997, 34, 433-459.

Nelson, C. R. and C. I. Plosser, "Trends and Random Walks in Macroeconomic Time Series," Journal of Monetary Economics, 1982, 10, 139-162.

Pribram, A. F., ed., Materialien zur Geschichte der Preise und Löhne in Österreich, Vol. 1, Wien: Carl Ueberreuters Verlag, 1938.

Runkle, D., "Vector Autoregressions and Reality," Journal of Business and Economic Statistics, 1987, 5, 437-442.

Steckel, R. H., "Stature and the Standard of Living," Journal of Economic Literature, 1995, XXXIII, 1903-1940.

Tanner, J., Foetus into Man. Physical Growth from Conception to Maturity, 2 ed., Canbridge, Mass.: Harvard University Press, 1990.

Williamson, J. G., "The Evolution of Global Labor Markets since 1830: Background Evidence and Hypotheses," Explorations in Economic History, 1995, 32, 141-196. 